\title{
Advancing Primate Research and Conservation Through the Use of Camera Traps: Introduction to the Special Issue
}

\author{
Paula A. Pebsworth • Marni LaFleur
}

Published online: 9 October 2014

(C) Springer Science+Business Media New York 2014

\begin{abstract}
Effective conservation and management of primates depend on our ability to accurately assess and monitor populations through research. Camera traps are proving to be useful tools for studying a variety of primate species, in diverse and often difficult habitats. Here, we discuss the use of camera traps in primatology to survey rare species, assess populations, and record behavior. We also discuss methodological considerations for primate studies, including camera trap research design, inherent biases, and some limitations of camera traps. We encourage other primatologists to use transparent and standardized methods, and when appropriate to consider using occupancy framework to account for imperfect detection, and complementary techniques, e.g., transect counts, interviews, behavioral observation, to ensure accuracy of data interpretation. In addition, we address the conservation implications of camera trapping, such as using data to inform industry, garner public support, and contributing photos to large-scale habitat monitoring projects. Camera trap studies such as these are sure to advance research and conservation of primate species. Finally, we provide commentary on the ethical considerations, e.g., photographs of humans and illegal activity, of using camera traps in primate research. We believe ethical considerations will be particularly important in future primate studies, although this topic has not previously been addressed for camera trap use in primatology or any wildlife species.
\end{abstract}

Keywords Cameratrap $\cdot$ Conservation ethics $\cdot$ Methods $\cdot$ Primates $\cdot$ Remote photography

\author{
P. A. Pebsworth \\ Department of Anthropology, University of Texas, San Antonio, TX 78666, USA \\ e-mail: ppebsworth@mac.com \\ P. A. Pebsworth \\ Department of Soil Science, Stellenbosch University, Stellenbosch, South Africa
}

M. LaFleur $(\bowtie)$

Institute for Population Genetics, University of Veterinary Medicine, 1220 Vienna, Austria

e-mail: marni.lafleur@gmail.com 


\section{Introduction}

At the XXIVth International Primatological Congress in Cancun, Mexico, a symposium entitled "Advancing Primate Research and Conservation through the Use of Camera Traps" brought primatologists together to discuss how camera trapping facilitates the study, management, and conservation of nonhuman primates. The symposium organizers (Marni LaFleur and Chia L. Tan) gathered information on the current state of camera trap applications in primate research and promoted the standardization of qualitative and quantitative methods. This forum provided camera trap users and would-be users the opportunity to discuss relevant topics, such as selecting the best hardware and accessories for one's project needs and budget, overcoming technical and methodological difficulties, and making reliable inferences from camera trap data. This special issue highlights some of the camera trap research presented at the IPS symposium in Cancun, and also addresses some of the discussion points that followed, e.g., data interpretation and standardized methods.

In this special issue editorial, we review a variety of camera trap applications that have been used in primatology: surveying rare species, assessing primate populations, and recording behavior. Next, we provide primatologists with methodological considerations for their camera trap studies. We then discuss how camera traps can be used to determine the conservation status of primate species and as a means promoting and protect primates. Finally, we address some of the ethical concerns that may arise when using camera traps in primate research, such as recording illegal activity and (potentially) protecting human anonymity. Surprisingly, given the extent of humanwildlife conflict on the global scale, ethical considerations and camera trap use are not discussed in any wildlife research that we are aware, but could be particularly important in cases of animal poaching and trafficking. We base our editorial on the information presented at the IPS symposium, the articles within the special issue, and the literature to date on camera trap use in primatology.

\section{Camera Trap Applications}

\section{Surveying Rare Species}

Natural resource, e.g., water, land, plants, management decisions are heavily influenced by the abundance and distribution of rare species (Thompson 2004). Unfortunately, by their very nature, rare species are a challenge to study because their populations may be clumped or sparsely distributed over a large range, and/or their behavior may be elusive (Thompson 2004). Rare species may also reside in remote areas where field conditions are difficult and traditional survey methods, e.g., direct observation, capture/recapture, are likely to be ineffective or impractical (Kierulff et al. 2004; Tan et al. 2013). In these instances, camera traps have proved to be an effective tool for surveying primates, without the need to observe the individuals directly or physically trap them (Fig. 1). Camera traps can record presence/absence of a rare or elusive species (Bezerra et al. 2014; Gerber et al. 2014), establish habitat requirements (Head et al. 2012; Numata et al. 2005), and document geographical range (Easton et al. 2011). To optimize the likelihood of capturing the focal subject, researchers have used lures (Bezerra et al. 
2014; Kierulff et al. 2004), strategically placed camera traps near critical resources, such as natural canopy bridges (Gregory et al. 2013), bamboo zones (Easton et al. 2011), and natural licks (Lhota et al. 2012). Additional methods of careful and targeted placement are described by Loken et al. (2013), Olson et al. (2012), and Tan et al. (2013).

Assessing Primate Populations

Primates are among the most threatened taxa, with almost half of the world's primate species in danger of extinction from habitat destruction, illegal wildlife trade, and commercial bushmeat hunting (Mittermeier et al. 2009). Primatologists need to monitor endangered populations, so that they can inform the public of a population's plight, encourage governments to conserve these species, and raise the necessary funds to introduce and implement critical conservation measures. Camera traps offer the possibility of continually monitoring a population indefinitely (or nearly indefinitely) and
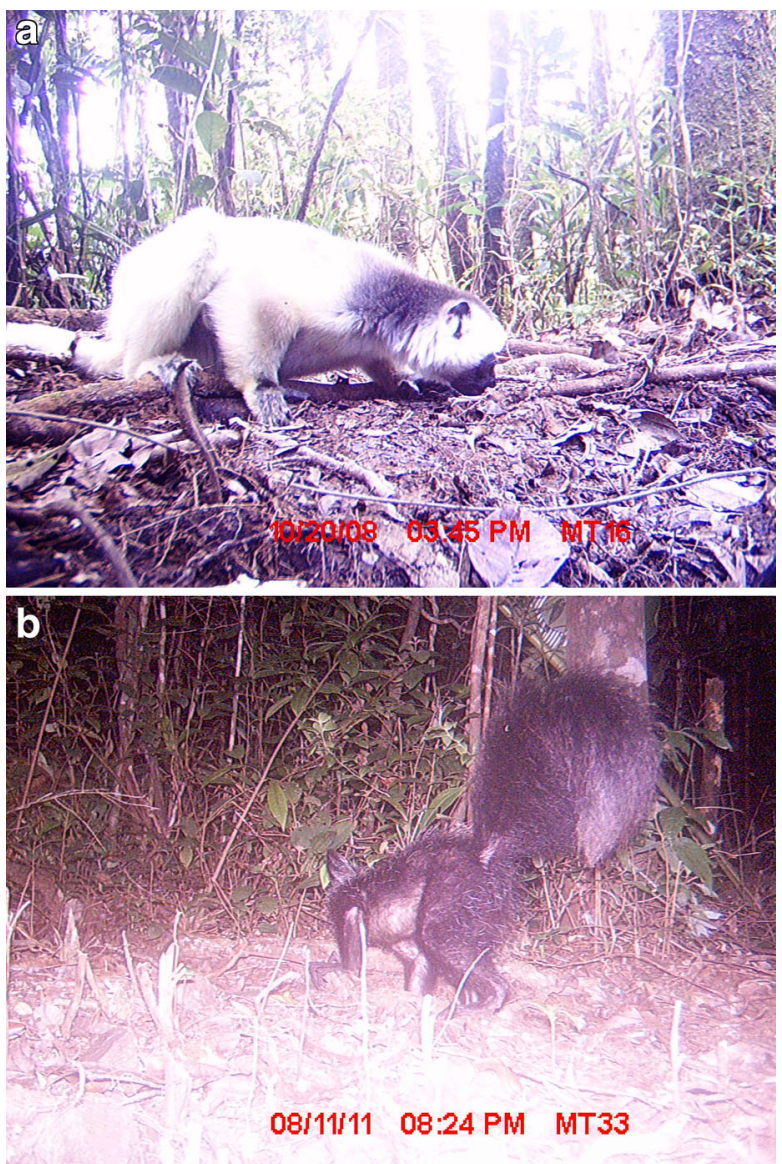

Fig. 1 (a) A very rare photo of a silky sifaka (Propithecus candidus) on the ground at the Anjanaharibe forest site in the Makira Natural Park, Madagascar. (b) An aye-aye (Daubentonia madagascariensis) at the Farankarina protected area near Masoala National Park, Madagascar. (Photos by Zach J. Farris.). 
can be used to assess primate demographic patterns (Fig. 2). For example, long-term camera trap projects can reconstruct group composition, including births, disappearances, and interbirth intervals (Galvis et al. 2014). In addition to demographic patterns, camera traps can be used to record specific primate behaviors, which are addressed next.

\section{Recording Primate Behavior}

Focal animal follows provide a wealth of data and information, as they document all behaviors of interest and primates' use of various resources (Altmann 1974). However, following animals in this way requires habituation, which is not always feasible or advisable (Jack et al. 2008; Souza-Alves and Ferrari 2010), as doing so may be detrimental to their health and wellbeing (Bezerra et al. 2014; Boyer-Ontl and Pruetz 2014; Butynski 2001; Williamson and Feistner 2003, 2011). Camera traps may provide a viable data collection alternative, in situations where animal follows and habituation
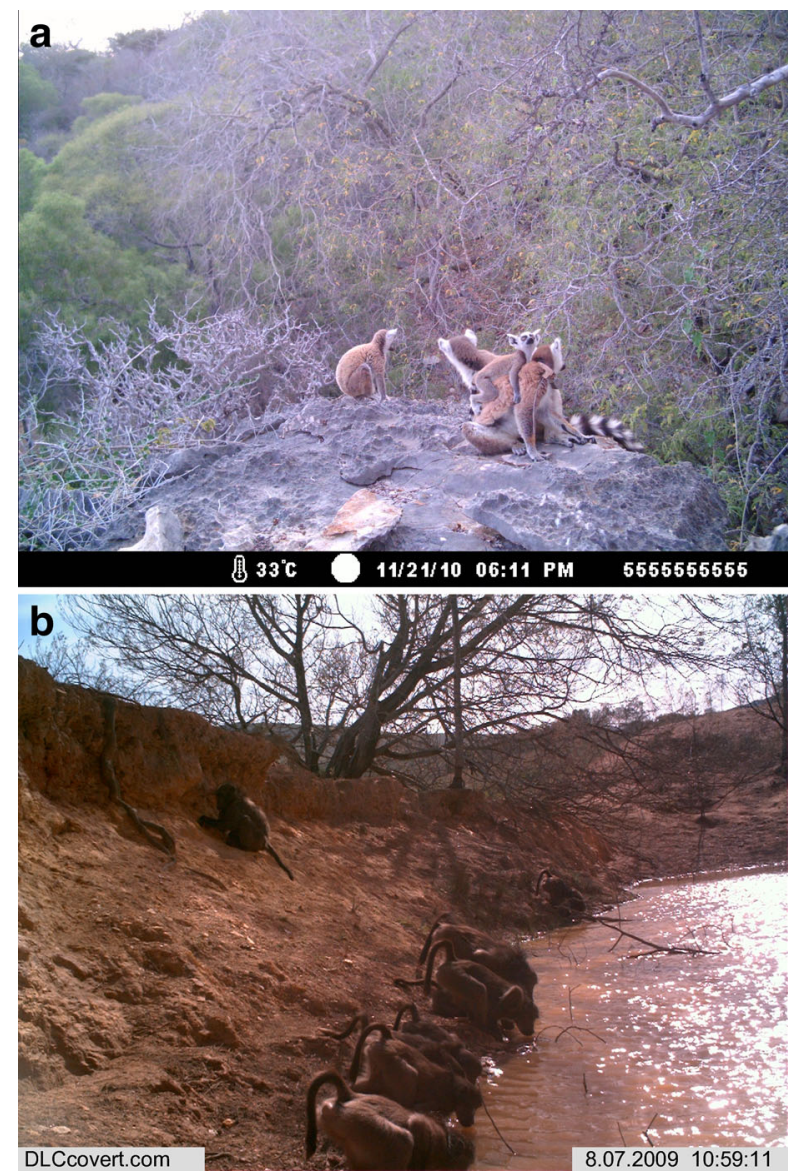

Fig. 2 (a) Ring-tailed lemurs (Lemur catta) with an infant at the Tsimanampetsotse National Park, Madagascar. (Photo by Marni LaFleur.) (b) Chacma baboons (Papio cynocephalus ursinus) congregate to drink water and eat soil at the Wildcliff Nature Reserve, South Africa. (Photo by Paula Pebsworth.). 
are not advisable. Primate studies have capitalized on camera traps' ability to monitor fixed locations where a specific behavior or resource use occurs, as well as interactions among and between species, as addressed in more detail next.

One of the first camera trap applications for recording behavior was geophagy, i.e., the deliberate consumption of earth materials (Fig. 3). Camera trap studies have documented which species frequent geophagy sites (Link et al. 2011; Matsubayashi et al. 2007), patterns of consumption (Galvis et al. 2014; Pebsworth et al. 2012), and possible seasonal effects of geophagy (Blake et al. 2010). Because geophagy sites are important contributors to a primate's overall health and they can be monitored with relative ease, these sites should be considered conservation priorities and target areas for gathering camera trap data (Matsubayashi et al. 2007; Pebsworth et al. 2012).

Other primate resources, such as foods, can also be monitored using camera traps. Studies focusing on the consumption of masting fruit resources (Miura et al. 1997; Prasad et al. 2010), seed dispersal (Miura et al. 1997), and of primates dropping or knocking off fruits that terrestrial animals then eat (Prasad et al. 2010), have informed
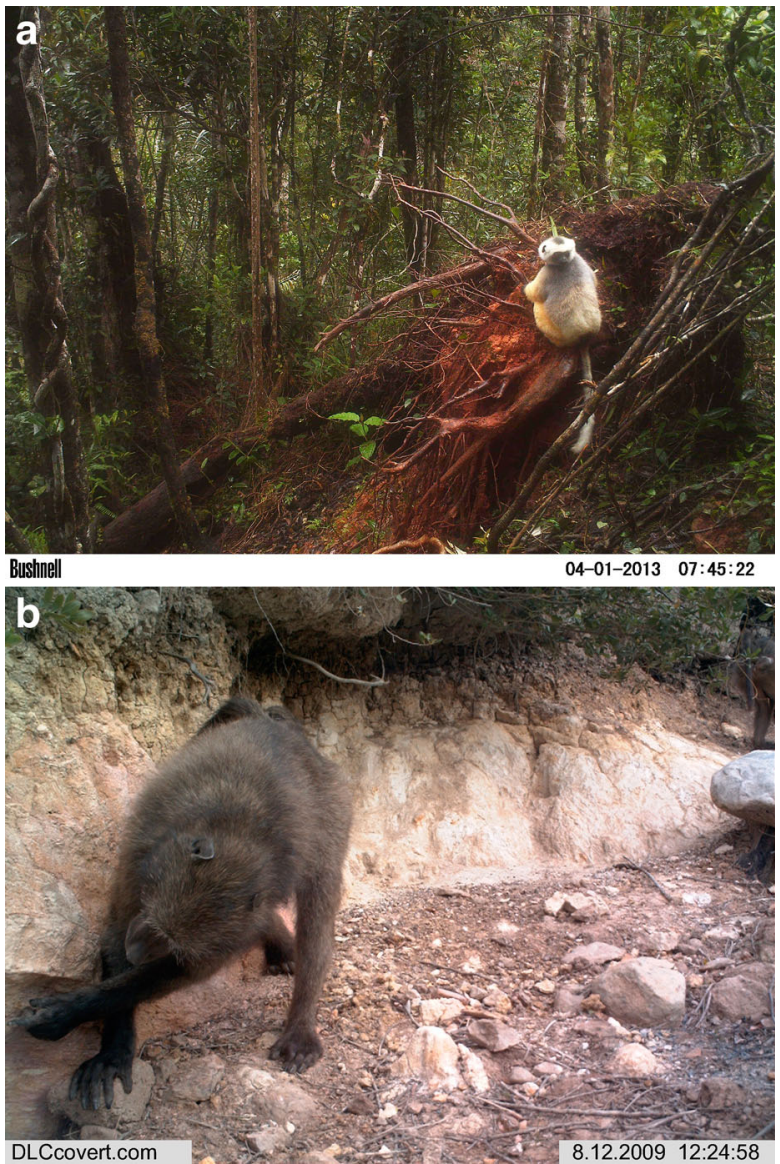

Fig. 3 (a) Diademed sifaka (Propithecus diadema) at a geophagy site in the Maromizaha Forest, Madagascar. (Photo from San Diego Zoo Global/University of Turin/GERP.) (b) Adult female chacma baboon (Papio cynocephalus ursinus) eating soil at the Wildcliff Nature Reserve, South Africa. (Photo by Paula Pebsworth.). 
researchers on how primates contribute to forest ecology. Moreover, video camera trapping showed that seasonal fruit abundance may influence interspecific competition between common chimpanzees (Pan troglodytes troglodytes), gorillas (Gorilla gorilla gorilla), and forest elephants (Loxodonta cyclotis) (Head et al. 2012). Camera trap research on habitat use patterns by sympatric chimpanzees and gorillas reflect the species' dietary preferences, in that chimpanzees are frugivorous and prefer montane forests and gorillas are folivores and are distributed across habitat types (Nakashima et al. 2013).

Unlike primate resources, predation events and predators are notoriously difficult to monitor. However, if you are extremely lucky, camera traps can be useful in documenting predation events (Fig. 4). Moreover, owing to the relative length of time camera traps are deployed, when compared with the amount of time one can spend observing, and the fact that observer presence can influence predator behavior, camera traps are also useful for detecting predators (Fig. 5) and understanding how primates react to their presence. Predator avoidance strategies have been detected via camera trap photos in white-bellied spider monkeys (Ateles belzebuth) and red howlers (Alouatta seniculus) (Blake et al. 2010; Link et al. 2011), and the authors suggest that these primates are more likely to use geophagy sites when they know where their predators are, even if the predators are nearby. Simlairly, ring-tailed lemurs (Lemur catta) stay in trees for longer periods when their largest aerial predators, Madagascar harrier hawks (Polyboroides radiata), are also present in the trees (LaFleur unpubl. data). This is likely because the hawks have large wingspans and cannot attack between branches (LaFleur unpubl. data).

Camera traps can also be used to assess other forms of behavioral plasticity. Loken et al. (2013) used camera traps to assess whether canopy connectivity influences terrestrial behavior in orangutans (Pongo pygmaeus morio), a predominately arboreal primate. This species of orangutan is native to Borneo, where habitat destruction and fragmentation have altered primate habitat (van Schaik et al. 2009). Camera traps documented that terrestriality is common in this population of orangutans and represents a locomotion strategy to overcome loss of canopy connectivity. Further, these results suggest orangutans may have more ecological flexibility than once thought.

Camera trap studies have shown that activity patterns vary more than traditional views, in such species as ring-tailed lemurs (Lemur catta: LaFleur et al. 2014), gray snub-nosed monkeys (Rhinopithecus brelichi: Tan et al. 2013), and savannah chimpanzees (Pan troglodytes versus: Boyer-Ontl and Pruetz 2014) (Fig. 6). Each of these primates has been traditionally classified as diurnal (Kirk and Kay 2004; $c f$. Donati et al. 2013 and Traina 2001 for Lemur catta). Nighttime activity in these primates has been attributed to avoiding extremely high daytime temperatures (Boyer-Ontl and Pruetz 2014) and exploiting ephemeral resources (LaFleur et al. 2014; Tan et al. 2013). Moreover, some of the nocturnal behaviors documented by camera traps have been novel, such as cave use and pool soaking by unhabituated groups of Pan troglodytes verus (Pruetz 2007). Such unexpected animal activity may have important implications for our understanding of species ecology, including activity budget, food intake, and predator avoidance, and highlights the behavioral flexibility of these primate species. 

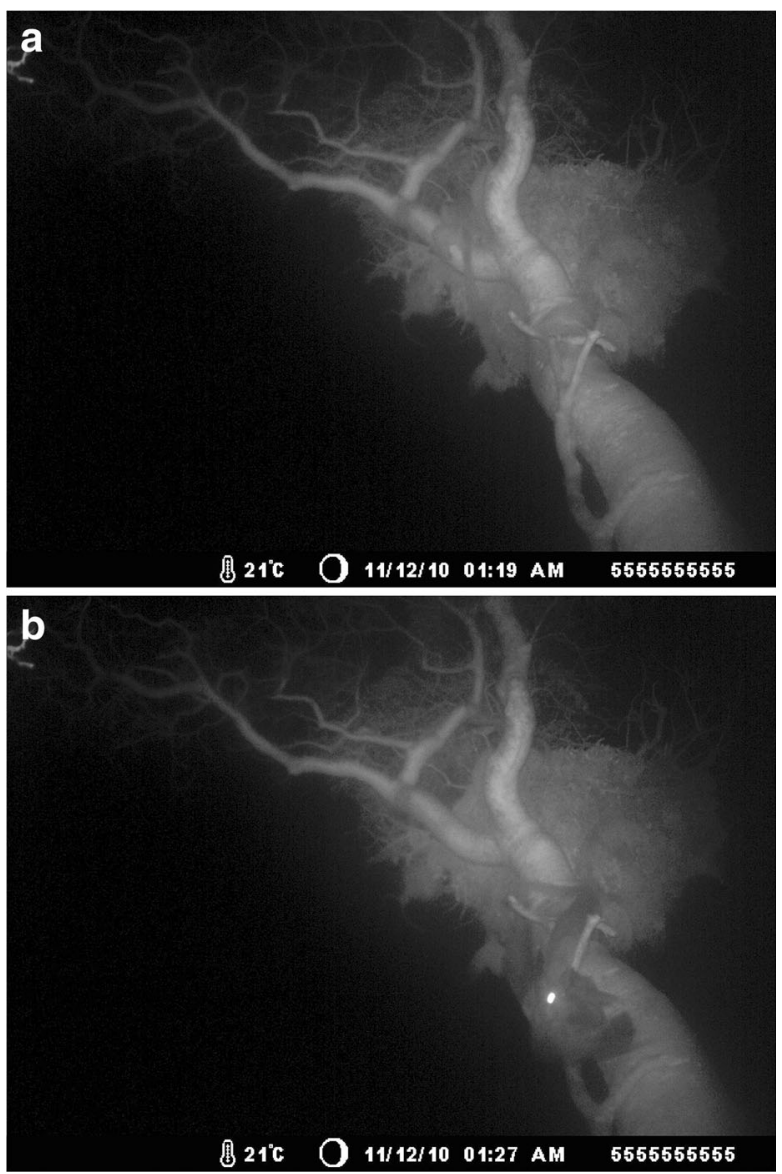

Fig. 4 (a) Madagascar's largest terrestrial predator, the fossa (Crypropracta ferox), entering the nest of the largest aerial predator, the Madagascar harrier hawk (Polyboroides radiata). (b) Six minutes later the fossa leaves with a hawk in its mouth. (Photos taken at the Tsimanampetsotse National Park, Madagascar by Marni LaFleur.).

\section{Methods}

Many different camera traps are available, and a researcher's site, objectives, and budget determine which camera is most appropriate. Camera trap technology is changing rapidly, so we do not discuss specific makes or models but offer some considerations for selecting a remotely triggered camera and how to determine whether it will be appropriate for a research site and objectives.

\section{Flash Type and Intensity}

Camera traps with infrared flash take color daytime and monochromatic nighttime photos, while camera traps with white flash take color photos regardless of light levels. Nighttime color photographs can be critical for conducting a faunal inventory and studies requiring individual recognition, but white flash may frighten target subjects 

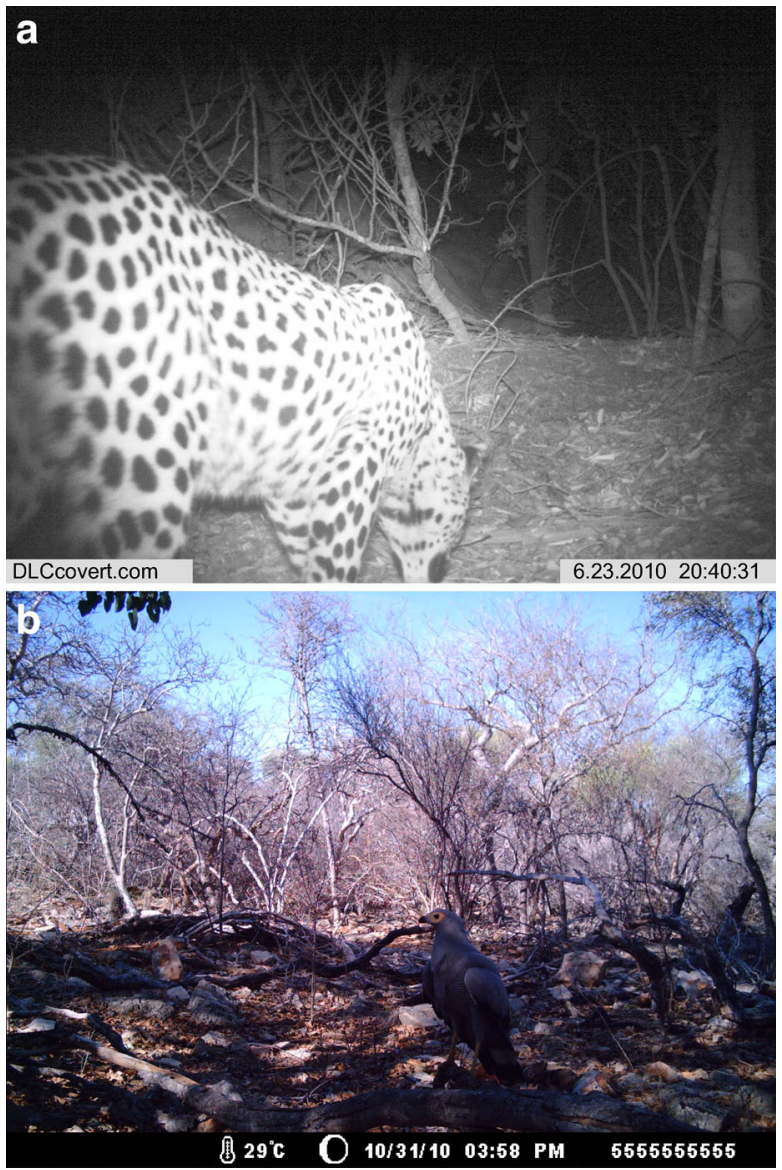

Fig. 5 (a) A Cape leopard (Panthera pardus) which shares its range with chacma baboons (Papio cynocephalus ursinus), and (b) a Madagascar harrier hawk (Polyboroides radiata), which shares its range with ring-tailed lemurs (Lemur catta). (Photos taken at Wildcliff Nature Reserve, South Africa by Paula Pebsworth and Tsimamampetsotse National Park, Madagascar by Marni LaFleur.).

and alter detection probabilities. In addition to flash type, researchers studying nocturnal primates may want to consider whether the camera automatically adjusts flash intensity based on the distance to the primate. This feature maximizes the probability of detecting primates while minimizing visible or audible cues that potentially alter behavior.

\section{Trigger Speed and Sensitivity}

How much time passes between camera activation and when a photograph is taken is critical to many studies. Most cameras employ a passive infrared sensor that activates at some time after it detects a difference in heat motion between the fore- and background temperature. Cameras with a short trigger delay $(<1 \mathrm{~s})$ are ideal for capturing relatively fast-moving, small, or solitary primates, whereas a longer trigger delay $(>1 \mathrm{~s})$ may be better for slow-moving, large, or group-living primates. False negative images, i.e., a 

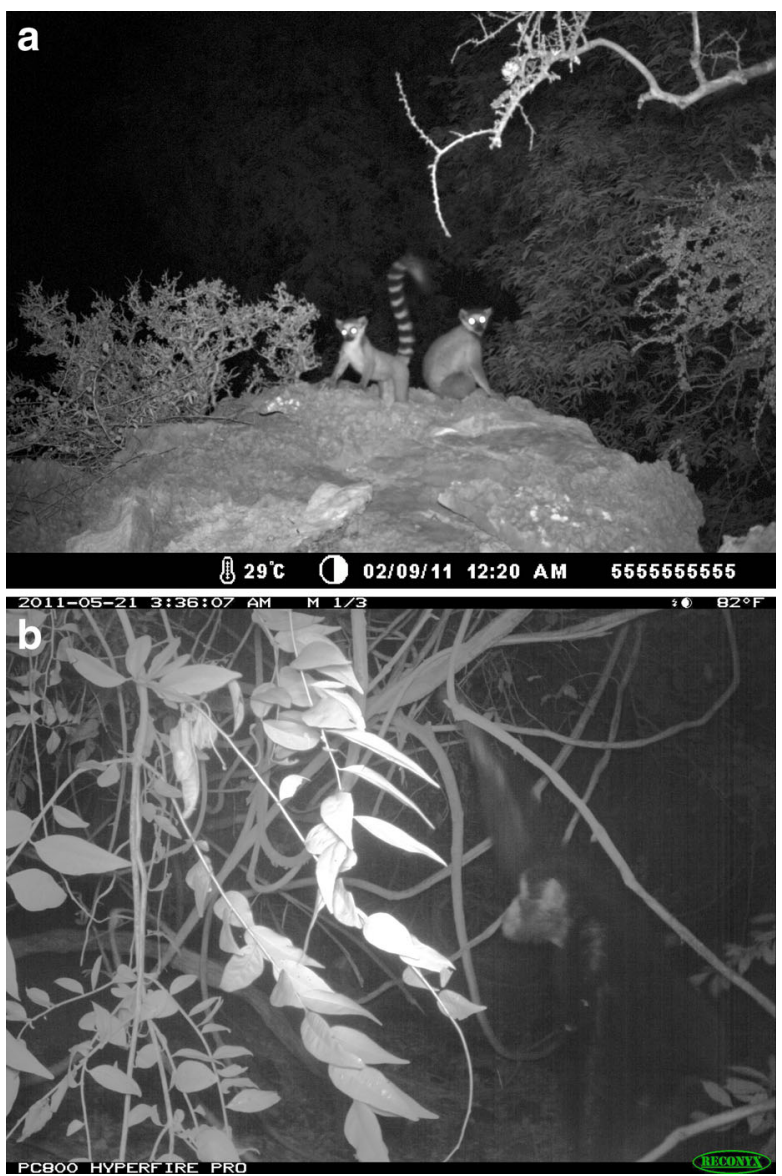

Fig. 6 (a) Ring-tailed lemur (Lemur catta) nighttime activity at the Tsimanampetsotse National Park, Madagascar. (Photo by Marni LaFleur.) (b) Senegalese chimpanzee (Pan troglodytes versus) nighttime activity. (Photo by Kelly Boyer Ontl.).

primate triggered the sensor but moved out of the frame before the photograph was taken, result from a trigger speed that is too slow, but cameras with fast trigger speed are often more expensive.

The sensitivity, or the camera's ability to detect heat motion, decreases when ambient temperature is low, or when the difference between ambient temperature and the subject's body temperature is small (i.e., $<2.7^{\circ} \mathrm{C}$ ) (Meek 2012). Decreased sensitivity can result in failure to trigger the camera trap. Alternatively, in very hot environments the camera can be highly sensitive and triggered more easily by nontarget movements, e.g., wind or moving vegetation (Gregory et al. 2013; Rovero et al. 2013). Sensitivity can be adjusted on most cameras.

Detection Zone

Detection area varies between camera models and is an important determinant in the number of photos taken. Some cameras use a conical detection zone, while others use 
horizontal bands and vertical axis zones (Rovero et al. 2013). Obviously, a larger detection zone allows a larger area to be monitored. The detection zones of some cameras are wider than their field of view, which can be useful in capturing fast-moving primates. However, wide detection zones may produce a surplus of blank photographs taken when primates enter the camera's detection zone but not the field of view. Cameras with narrower detection zones produce fewer blank photographs but may also fail to detect primates that move quickly or are not well centered in front of the camera.

\section{Memory}

Most camera traps are digital and require secure digital memory cards. Larger card sizes, e.g., 4-32 GB, allow for longer deployment time, a large number of photographs, or video recording.

\section{Security}

Camera traps are expensive and may be difficult to replace once in the field. To prevent or discourage theft, they can be attached to trees or other substrates with security cables. Cameras can also be housed in external metal security boxes, which have the extra protection of being tamper-proof and can also be locked and securely attached.

\section{Effects of Climate}

Moisture and extreme temperatures affect image quality and power. Researchers combat high humidity and precipitation by placing an internal desiccant inside the camera housing to prolong dry conditions (Blake et al. 2010; Miura et al. 1997). In addition, covering the camera in a thin transparent polyethylene bag or wrap can act as a barrier to moisture and debris (Numata et al. 2005). Intense sunlight can also impact camera performance, as it degrades plastic lenses.

In addition to image quality, camera trap performance declines with extreme temperatures, e.g., $<0^{\circ} \mathrm{C}$ and $>30^{\circ} \mathrm{C}$. In very cold temperatures, alkaline batteries quickly discharge, so lithium or nickel metal hydride (NiMH) rechargeable batteries are the best option. NiMH rechargeable batteries fail sooner in hot weather (when temperatures exceed $32^{\circ} \mathrm{C}$ ), and alkaline and lithium batteries are preferable.

Small portable solar panels with built-in lithium polymer batteries are also available for camera traps. These are safe for use in extreme temperatures and are automatically chosen as the main power source for the cameras, although we recommend internal batteries as backup to solar power.

Trap Days and Camera Placement

Camera trap days are the number of 24-h periods that cameras are employed, multiplied by the number of cameras in operation (Blake et al. 2010; Rovero et al. 2013). The research goals determine the number of camera trap days necessary for data collection. For example, LaFleur et al. (2014) determined in less than a month that Lemur catta 
frequently engaged in nighttime activity. However, rare behaviors or infrequently seen species will likely require extended periods of monitoring. In species inventory studies, an accumulation curve can be used to assess if the duration of sampling has sufficiently captured species present (Tobler et al. 2008). In this case, time needed to carry out a survey is inversely proportional to the number of camera traps used. The more camera traps used, the more quickly the accumulation curve will level off. However, the distance between cameras may be important, as cameras that are placed nearby one another may not produce photographs that are independent events. This also applies to the time lag between photographs. Researchers must think carefully about how and why they consider photographs independent, as this will influence the results (LaFleur et al. 2014; Tan et al. 2013).

Camera traps can be placed strategically or systematically. Systematic placement involves determining set intervals for cameras. In this case, camera placement may be based on a grid (Gerber et al. 2012; Head et al. 2012), in convenient areas such as on trails (Farris et al. 2014; Head et al. 2012), or randomly (Nakashima et al. 2013). Random sampling aims to meet certain statistical requirements, to achieve independent sampling (Nakashima et al. 2013).

\section{Assessment Biases}

All sampling methods have biases, and camera traps are no exception. Images captured can be biased by species-specific characteristics, as camera trap detection is higher in gregarious species that forage and travel together than solitary individuals (Treves et al. 2010) and they are also more effective at detecting smaller, solitary, and nocturnal species than wildlife patrol units (Burton 2012). Population assessments using camera traps can also be affected by anthropogenic disturbances and human presence. For example, Gray and Phan (2011) reported that camera trap detection was lower in areas within a day's walk from human settlement and that even after 750 nights of surveys, camera traps failed to capture all species known to exist within the Phnom Prich Wildlife Sanctuary.

\section{Correcting Camera Trap Biases}

When possible, researchers should compare sampling methods to determine whether their data are biased. Ideally, biased camera trap data should be corrected or offset by using an occupancy framework (Gerber et al. 2014), and/or combining camera trap surveys with complementary methods. Many established methods have been used in combination with camera trap surveys to improve data reliability, e.g., direct observation and spot counts (Galvis et al. 2014; Pickles et al. 2011; and line transects, Farris et al. 2014), although other methods also have inherent biases such as variation in detection, small sample size, and low precision (Gerber et al. 2014). When camera traps and direct observation fails to establish species presence, indirect observation (spoor, feces, nest, carcasses) can be employed (Nakashima et al. 2013; Ross and Reeve 2003; Stevens et al. 2011). 


\section{Implications for Primate Conservation}

Primatologists are concerned with the survival of their research taxa (Setchell 2013). Baseline analyses and environmental monitoring are essential components of conservation management, and camera traps are effective tools both alongside and apart from traditional habitat and animal monitoring programs (Ahumada et al. 2013; Galvis et al. 2014). For example, camera trap monitoring and surveillance of Peruvian primates showed that trap success and encounter rates dramatically decreased immediately after land clearance and gas pipeline installation; however, animals resumed use of land bridges after construction (Gregory et al. 2013). These data were used to inform gas and oil developers, who continued to maintain corridors when clearing forested areas (Gregory et al. 2013). Another camera trap study documented Gorilla gorilla diehli for the first time in Cameroon's Kagwene Gorilla Sanctuary (Wildlife Conservation Society, 2012). This elusive species has rarely been viewed directly, and researchers and conservation organizations discourage habituation because of potential hunting pressures. The Wildlife Conservation Society used these data as part of community and public awareness campaigns, and footage served to inspire local people, governments, and the global community to protect and conserve this Critically Endangered great ape. Data such as these can enable conservation planners to assess and progress toward conservation goals and to target and design interventions (Gregory et al. 2013; O'Brien et al. 2010; Wegge et al. 2004).

The largest globally coordinated camera trap monitoring project, Tropical Ecological Assessment \& Monitoring Network (TEAM), also provides opportunities for primate conservation planning through camera trap data (www.teamnetwork.org). TEAM report activities of terrestrial vertebrates and currently monitor 16 tropical forest sites across Africa, Asia, and Latin America. Camera trap data are collected according to strict protocols, and all researchers can access the data via an online database. Primatologists can also contribute data to this project but must adhere to guidelines including the use of a minimum of 60 camera traps per project. More information on TEAM can be found on their website (www.teamnetwork.org).

\section{Ethical Considerations}

Field primatologists face a complex array of issues related to primate subjects, which often stem from the competing need for resources by wild primates and humans, and/or the management of habitat by local governments or officials (Wolfe 2005). Several excellent publications have resulted from the recent initiative to highlight the ethical dilemmas faced by field primatologists (Fedigan 2010; MacKinnon and Riley 2010; Malone et al. 2010), but the use of camera traps has not been addressed directly. In fact, to our knowledge, ethical concerns of camera trapping have not been addressed in the wildlife literature.

Some of the ethical considerations of using camera traps are the same as those encountered by conducting fieldwork in general, such as potentially witnessing illegal activity, while others are unique to camera traps, including what constitutes informed consent by humans that are photographed. Inevitably, whether intentional or not, researchers employing camera traps will capture photographs of humans. We thus need 
to determine under what circumstances, if any, these photos are used. Human activities could, of course, be the focus of our research, as we may want to document human presence or human impact on nonhuman primate habitats. In these instances, permission from the researcher's Institutional Review Board (IRB) or similar for human subjects is likely to be necessary. However, if photographs of people are merely a "by-product" of data collection, what should we do with these unintended data, and should we still seek IRB approval?

Ethnographers generally provide copies of data to all informants and go to great lengths to protect informant identity (Murchison 2010). Should we adopt similar policies? One could imagine providing photos to each person captured by cameras quickly becoming unmanageable. Alternatively, it may be more suitable to provide information, rather than actual photographs, to local people with reference to the location of cameras and goals of research. Along these lines, and similar to some of the concerns of sociocultural anthropologists, we also need to consider data storage policies and decide who will have access to these images. What should we do if local authorities request (or demand) copies of our camera trap images as a condition of our research, or even after the research has taken place? Can we protect the anonymity of the people in our photos, and, with reference to illegal activities, do we want to? Illegal activity is likely to be the most ethically difficult (and common) potential scenario researchers will face with camera trap studies. In some instances, providing photographic documentation to local authorities on illegal harvesting of forest resources, hunting, or capturing animals could aid forest protection and prosecution of wrongdoers. Yet, in other cases, this information may do little to further our conservation agendas and could act to alienate local people and threaten our future research and conservation prospects.

There are no simple answers to these complex issues, but we hope to initiate a discussion on some of the ethical conundrums primatologists may face when using camera traps and encourage forethought related to the conflicts that may arise when using camera traps in primate research.

\section{Conclusion}

The articles in this special issue reflect a variety of primate studies that employed camera traps and collectively provide a summary of the applications primatologists are using. Camera traps are proving to be an effective tool in the documentation of primate ecology and spatial distribution patterns. Further, as human activity continues to alter primate habitat and behavior, we suggest camera traps can monitor primate populations that should not be habituated or whose behavior would be greatly altered by human presence. However, camera traps are not a research panacea and have inherent biases. We encourage primate researchers to test and acknowledge these limitations and to use corrective and complementary techniques when they are warranted. We also recommend that researchers adhere to methodological protocols and report qualitative and quantitative methods accurately to facilitate intersite and -species comparisons. We particularly encourage further research into the ethical concerns raised by using camera traps in primatological field research. 
Acknowledgments We thank the editor of International Journal of Primatology, Dr. Joanna Setchell, for help and assistance in the production of this special issue and particularly this editorial. In addition, we thank our co-guest editor, Chia Tan, and Keith Riggle for their support, suggestions, and reviews of earlier versions of the manuscript. We thank the symposium participants (Advancing Primate Research and Conservation through the Use of Camera Traps) and attendees for their contributions and thought-provoking discussion points. Funding was provided by the Austrian Academy of Science (M. LaFleur) and Wilderness Wildlife Trust (P. A. Pebsworth).

\section{References}

Ahumada, J. A., Hurtado, J., \& Lizcano, D. (2013). Monitoring the status and trends of tropical forest terrestrial vertebrate communities from camera trap data: A tool for conservation. PLoS One, 8(9), e73707.

Altmann, J. (1974). Observational study of behavior: Sampling methods. Behaviour, 227-267.

Bezerra, B. M., Bastos, M., Souto, A., Keasey, M. P., Eason, P., Schiel, N., \& Jones, G. (2014). Camera trap observations of nonhabituated critically endangered wild blonde capuchins, Sapajus flavius (formerly Cebus flavius). International Journal of Primatology, 35. doi:10.1007/s10764-014-9782-4.

Blake, J. G., Guerra, J., Mosquera, R. T., Loiselle, B. A., \& Romo, D. (2010). Use of mineral licks by whitebellied spider monkeys (Ateles belzebuth) and red howler monkeys (Alouatta seniculus) in eastern Ecuador. International Journal of Primatology, 31, 471-483.

Boyer-Ontl, K., \& Pruetz, J. (2014). Giving the forest eyes: The benefits of using camera traps to study unhabituated chimpanzees (Pan troglodytes verus) in southeastern Senegal. International Journal of Primatology, 35. doi:10.1007/s10764-014-9783-3.

Burton, C. A. (2012). Critical evaluation of a long-term based wildlife monitoring program in West Africa. Biodiversity Conservation, 21, 3079-3094.

Butynski, T. M. (2001). Africa's great apes. In B. B. Beck, T. S. Stoinski, M. Hutchins, T. L. Maple, B. Norton, A. Rowan, E. F. Stevens, \& A. Arluke (Eds.), Great apes \& humans: The ethics of coexistence (pp. 3-56). Washington, DC: Smithsonian Institution Press.

Donati, G., Santini, L., Razafindramanana, J., Boitani, L., \& Borgognini-Tarli, S. (2013). Unexpected nocturnal activity in "diurnal" Lemur catta supports cathemerality as one of the key adaptations of the lemurid radiation. American Journal of Physical Anthropology, 150(1), 99-106.

Easton, J., Chao, N., Mulindahabi, F., Ntare, N., Rugyerinyange, L., \& Ndikubwimana, I. (2011). Status and conservation of the only population of the vulnerable owl-faced monkey Cercopithecus hamlyni in Rwanda. Oryx, 45, 435-438.

Farris, Z. J., Karpanty, S. M., Ratelolahy, F., \& Kelly, M. J. (2014). Predator-primate distribution, activity, and co-occurrence in relation to habitat and human activity across fragmented and contiguous forests in northeastern Madagascar. International Journal of Primatology, 35. doi:10.1007/s10764-014-9786-0.

Fedigan, L. M. (2010). Ethical issues faced by field primatologists: Asking the relevant questions. American Journal of Primatology, 72, 754-771.

Galvis, N., Link, A., \& Di Fiore, A. (2014). A novel use of camera traps to study the demography and life history in wild animals: A case study of spider monkeys (Ateles belzebuth). International Journal of Primatology, 35. doi:10.1007/s10764-014-9791-3.

Gerber, B. D., Karpanty, S. M., \& Randrianantenaina, J. (2012). Activity patterns of carnivores in the rain forests of Madagascar: Implications for species coexistence. Journal of Mammalogy, 93(3), 667-676.

Gerber, B. D., Williams, P. J., \& Bailey, L. L. (2014). Primates and cameras: Noninvasive sampling to make population-level inferences while accounting for imperfect detection. International Journal of Primatology, 35. doi:10.1007/s10764-014-9761-9.

Gray, T. N. E., \& Phan, C. (2011). Habitat preferences and activity patterns of the larger mammal community in Phnom Prich Wildlife Sanctuary, Cambodia. The Raffles Bulletin of Zoology, 59, 311-318.

Gregory, T., Carrasco Rueda, F., Deichmann, J., Kolowski, J., Costa Faura, M., Dallmeier, F., \& Alonso, A. (2013). Methods to establish canopy bridges to increase natural connectivity in linear infrastructure development. Society of Petroleum Engineers, SPE12LAHS-P-157.

Head, J. S., Robbins, M. M., Mundry, R., Makaga, L., \& Boesch, C. (2012). Remote video-camera traps measure habitat use and competitive exclusion among sympatric chimpanzee, gorilla and elephant in Loango National Park, Gabon. Journal of Tropical Ecology, 28, 571-583. 
Jack, K. M., Lenz, B. B., Healan, E., Rudman, S., Schoof, V. A. M., \& Fedigan, L. M. (2008). The effects of observer presence on the behavior of Cebus capucinus in Costa Rica. American Journal of Primatology, 70, 490-494.

Kierulff, M. C., Santos, G. R., Canale, G. R., Guidorizzi, C. E., \& Cassano, C. R. (2004). The use of cameratraps in a survey of the buff-headed capuchin monkey, Cebus xanthosternos. Neotropical Primates, 12, 56-59.

Kirk, E. C., \& Kay, R. F. (2004). The evolution of high visual acuity in the Anthropoidea. In Ross C. F. \& Kay R. F. (eds.), Anthropoid origins: New visions (pp. 539-602). New York: Kluwer Academic/Plenum Press.

LaFleur, M., Sauther, M., Cuozzo, F., Yamashita, N., Youssouf, I. A. J., \& Bender, R. (2014). Cathemerality in wild ring-tailed lemurs (Lemur catta) in the spiny forest of Tsimanampetsotsa National Park: Camera trap data and preliminary behavioral observations. Primates, 55(2), 207-217.

Lhota, S., Loken, B., Spehar, S., Fell, E., Pospech, A., \& Kasyanto, N. (2012). Discovery of Miller's grizzled langur (Presbytis hosei canicrus) in Wehea forest confirms the continued existence and extends known geographical range of an endangered primate. American Journal of Primatology, 74, 193-198.

Link, A., de Luna, A. G., Arango, R., \& Diaz, M. C. (2011). Geophagy in brown spider monkeys (Ateles hybridus) in a lowland tropical rainforest in Colombia. Folia Primatologica, 82, 25-32.

Loken, B., Spehar, S. \& Rayadin, Y. (2013). Terrestriality in the bornean orangutan (Pongo pygmaeus morio) and implications for their ecology and conservation. American Journal of Primatology, 75, 1129-1138. doi:10.1002/ajp.22174

Mackinnon, K. C., \& Riley, E. P. (2010). Field primatology of today: Current ethical issues. American Journal of Primatology, 72, 749-753.

Malone, N. M., Fuentes, A., \& White, F. J. (2010). Subjects of knowledge and control in field primatology. American Journal of Primatology, 72, 779-784.

Matsubayashi, H., Lagan, P., Majalap, N., Tahgah, J., Sukor, J. R. A., \& Kitayama, K. (2007). Importance of natural licks for the mammals in Bornean inland tropical rain forests. Ecological Research, 22, 742-748.

Meek, P. D. (2012). Refining and improving the use of camera trap technology for wildlife management and research in Australia and New Zealand. Final report. Canberra, Australia: The Winston Churchill Memorial Trust of Australia.

Mittermeier, R. A., Wallis, J., Rylands, A. B., Ganzhorn, J. U., Oates, J. F., Williamson, E. A., \& Schwitzer, C. (2009). Primates in peril: The world's 25 most endangered primates 2008-2010. Primate Conservation, 24, 1-57.

Miura, S., Yasuda, M., \& Ratnam, L. C. (1997). Who steals the fruits? Monitoring frugivory of mammals in a tropical rain-forest. The Malayan Nature Journal, 50, 183-193.

Murchison, J. (2010). Ethnography essentials: Designing, conducting and presenting your research. San Francisco: Jossey-Bass.

Nakashima, Y., Iwata, Y., Ando, C., Nze Nkoguee, C., Inoue, E., Akomo, E. F. O., \& Yamagiwa, J. (2013). Assessment of landscape scaledistribution of sympatric great apes in African rainforests: Concurrent use of nest and camera trap surveys. American journal of primatology, 75(12), 1220-1230.

Numata, S., Okuda, T., Sugimoto, T., Nishimura, S., Yoshida, K., Quah, E. S., Yasuda, M., Muangkhum, K., \& Noor, N. S. M. (2005). Camera trapping: A non-invasive approach as an additional tool in the study of mammals in Pasoh Forest Reserve and adjacent fragmented areas in peninsular Malaysia. Malayan Nature Journal, 57, 29-45.

O’Brien, T. G., Baillie, J. E. M., Krueger, L., \& Cuke, M. (2010). The Wildlife Picture Index: monitoring top trophic levels. Animal Conservation, 13, 335-343.

Olson, E. R., Marsh, R. A., Bovard, B. N., Randrianarimanana, H. L. L., Ravaloharimanitra, M., Ratsimbazafy, J. H., \& King, T. (2012). Arboreal camera trapping for the critically endangered greater bamboo lemur Prolemur simus. Oryx, 46, 593-597.

Pebsworth, P. A., Bardi, M., \& Huffman, M. A. (2012). Geophagy in chacma baboons: Patterns of soil consumption by age class, sex, and reproductive state. American Journal of Primatology, 74, 48-57.

Pickles, R. S. A., McCann, N. P., \& Holland, A. P. (2011). Mammalian and avian diversity of the Rewa Head, Rupununi, Southern Guyana. Biota Neotropica, 11, 237-251.

Prasad, S., Pittet, A., \& Sukumar, R. (2010). Who really ate the fruit? A novel approach to camera trapping for quantifying frugivory by ruminants. Ecological Research, 25, 225-231.

Pruetz, J. D. (2007). Evidence of cave use by savanna chimpanzees (Pan troglodytes verus) at Fongoli, Senegal: Implications for thermoregulatory behavior. Primates, 48(4), 316-319.

Ross C., \& Reeve N. (2003). Survey and census methods: population distribution and density. In Setchell JM, Curtis JC, (Eds.). Field and laboratory methods in primatology (pp 90-109). Cambridge, Cambridge University Press.

Rovero, F., Zimmermann, F., Berzi, D., \& Meek, P. (2013). "Which camera trap type and how many do I need?" A review of camera features and study designs for a range of wildlife research applications. Hystrix, the Italian Journal of Mammalogy, 24(2), 148-156. 
Setchell, J. M. (2013). Editorial: The top 10 questions in primatology. International Journal of Primatology, 34(4), 647-661.

Souza-Alves, J. P., \& Ferrari, S. F. (2010). Responses of wild titi monkeys, Callicebus coimbrai (Primates: Platyrrhini: Pitheciidae), to the habituation process. Zoologica, 27, 861-866.

Stevens, K., Dehgan, A., Karlstetter, M., Rawan, F., Tawhid, M. I., Ostrowski, S., Ali, J. M., \& Ali, R. (2011). Large mammals surviving conflict in the eastern forests of Afghanistan. Oryx, 45, 265-271.

Tan, C. L., Yang, Y., \& Niu, K. (2013). Into the night: Camera traps reveal nocturnal activity in a presumptive diurnal primate, Rhinopithecus brelichi. Primates, 54, 1-6.

Thompson, W. (Ed.). (2004). Sampling rare or elusive species: Concepts, designs, and techniques for estimating population parameters. Washington, DC: Island Press.

Tobler, M. W., Carrilo-Percastegui, S. E., Pitman, R. L., Mares, R., \& Powell, G. (2008). An evaluation of camera-traps for inventorying large-and medium-sized terrestrial rainforest mammals. Animal Conservation, 11, 169-178.

Traina, A. (2001). Activity pattern and feeding behavior of ring-tailed lemurs (Lemur catta) at Berenty Reserve in Madagascar during the day and night. Folia Primatologica, 72, 188.

Treves, A., Mwima, P., Plumptre, A. J., \& Isoke, S. (2010). Camera-trapping forest-woodland wildlife of western Uganda reveals how gregariousness biases estimates of relative abundance and distribution. Biological Conservation, 143, 521-528.

Van Schaik, C. P., Marshall, A. J., \& Wich, S. A. (2009). Geographic variation in orangutan behavior and biology. In S. A. Wich, S. S. Utami Atmoko, T. Mitra Seteia, \& C. P. van Schaik (Eds.), Orangutans: Geographic variation in behavioral ecology and conservation (pp. 351-362). Oxford: Oxford University Press.

Wegge, P., Pokheral, C. P., \& Jnawali, S. R. (2004). Effects of trapping effort and trap shyness on estimates of tiger abundance from camera trap studies. Animal Conservation, 7, 251-256.

Wildlife Conservation Society. (2012). Rare glimpse of world's rarest gorilla. Science Daily, May 8, 2012. Retrieved from www.sciencedaily.com/releases/2012/05/120508124500.htm.

Williamson, E. A , \& Feistner, A. (2011) Habituating primates: Processes, techniques, variables and ethics (2nd Edition). In J. M., Setchell, D. J., Curtis (Eds.). Field and Laboratory Methods in Primatology: A practical guide, 2nd ed, (pp. 33-50). Cambridge: Cambridge University Press

Wolfe, L. (2005). Field primatologists: Duties, rights, and obligations. In T. R. Turner (Ed.), Biological anthropology and ethics (pp. 15-26). Albany: State University of New York Press. 